\title{
ATIVIDADES TERAPÊUTICAS DA PIMENTA-VERMELHA (CAPSICUM SP. - SOLANACEAE) E PIMENTA-DO-REINO (PIPER NIGRUM L.- PIPERACEAE)
}

\author{
Rogerio da Silva Veiga1, Maria Cristina Marcucci ${ }^{2,3}$. \\ ${ }^{1}$ Faculdade de Ciências Médicas da Santa Casa de São Paulo. \\ ${ }^{2}$ Docente do Programa de Pós-graduação Stricto sensu da Universidade Anhanguera de São Paulo. \\ ${ }^{3}$ Endereço para correspondência: Programa de Pós-graduação Stricto sensu em Farmácia e Biotecnologia da \\ Universidade Anhanguera de São Paulo. Av. Raimundo Pereira de Magalhães, 3305. Pirituba, São Paulo, Brasil. \\ CEP 05145-200. Fone/FAX: 0055113512-8400; e-mail: cristina.marcucci@anhanguera.com
}

\section{Resumo}

São diversas as atividades terapêuticas que podem ser aplicadas tanto na dietoterapia como na farmacoterapia atribuídas às espécies popularmente conhecidas como pimentas-vermelhas (Capsicum sp.), onde a principal parte utilizada, o fruto inteiro, é constituído principalmente por capsaicina e a pimentado-reino (Piper nigrum L.), onde também se utiliza o fruto constituído principalmente por piperina. A fundamentação das pesquisas, que servem de ponto de partida para a maioria dos estudos, está embasada no uso tradicional. Esses efeitos estão relacionados desde as diversas fases do processo digestivo tais como o estímulo da secreção salivar e o estímulo e a inibição de secreções gástricas, intestinais, pancreáticas e biliares até o metabolismo dos carboidratos e lipídeos assim como as consequências que isso gera como a proteção endotelial, atividade anti-inflamatória e antitumoral, por exemplo. Embora haja uma ampla margem de segurança consequente de uma também ampla janela terapêutica, a cautela no uso dessas ferramentas terapêuticas deve sempre estar presente.

Palavras chave: Fitoterapia, pimentas, drogas vegetais, plantas medicinais, especificações técnicas, controle de qualidade.

\section{Introdução}

As especiarias e os temperos frequentemente utilizados na gastronomia ocidental e oriental podem modificar a microbiota tanto estimulando os micro-organismos que protegem contra o câncer quanto aqueles que o causam. As especiarias utilizadas na culinária geralmente servem como antioxidantes, mas quando fracionadas, ou seja, quando partes dos seus constituintes (ex.: óleo essencial) são isolados, podem servir como pró-oxidantes na exposição intensa e por longos períodos ${ }^{(8)}$.

As espécies vegetais do gênero Capsicum sp. são utilizadas (ex.: Capsicum baccatum Kunth. - Pimenta - dedo-de-moça, figura 1) como especiaria, tempero, condimento e até alimento principal. Os frutos dessas espécies contribuem para a pretensão anti-inflamatória na nutrição. São ferramentas consagradas pelos benefícios observados em culturas que as adotam em dietas tradicionais ${ }^{(2)}$.

A pimenta-do-reino (Piper nigrum, figura 2), é conhecida também por possuir propriedades semelhantes às da pimenta-vermelha (Capsicum sp.), mas com menos potência porque não aumenta a expressão de citocinas anti-inflamatórias, somente suprime as citocinas pró-inflamatórias. $\mathrm{O}$ principal constituinte da pimenta-do-reino, a piperina, é estável ao calor do cozimento e do micro -ondas. O fato é que ela é liberada mediante o cozimento, então recomenda-se um uso moderado ${ }^{(9)}$. 


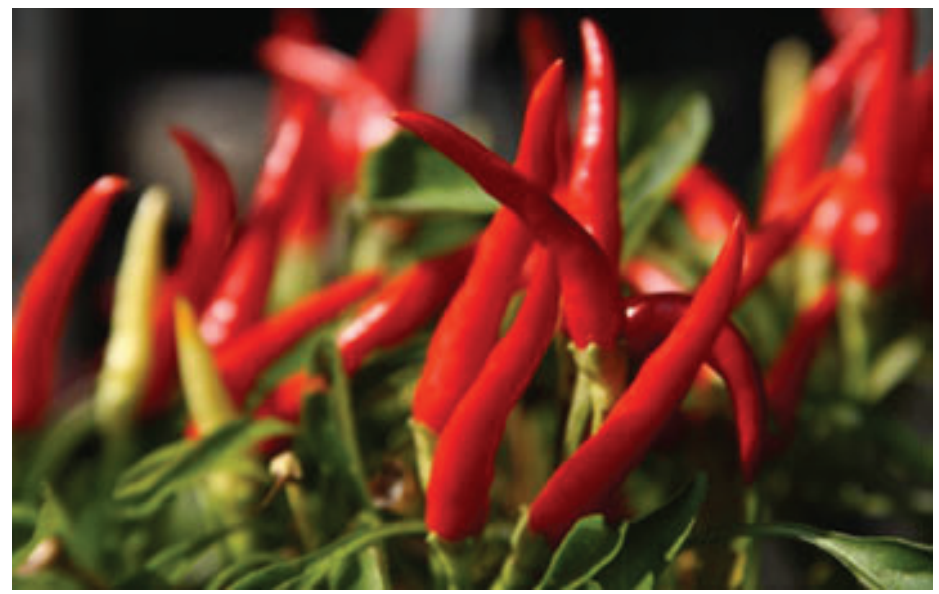

Figura 1: Pimenta Capsicum baccatum Kunth.

Fonte: https://www.saudehoje.net/pimenta-dedo-de-moca/

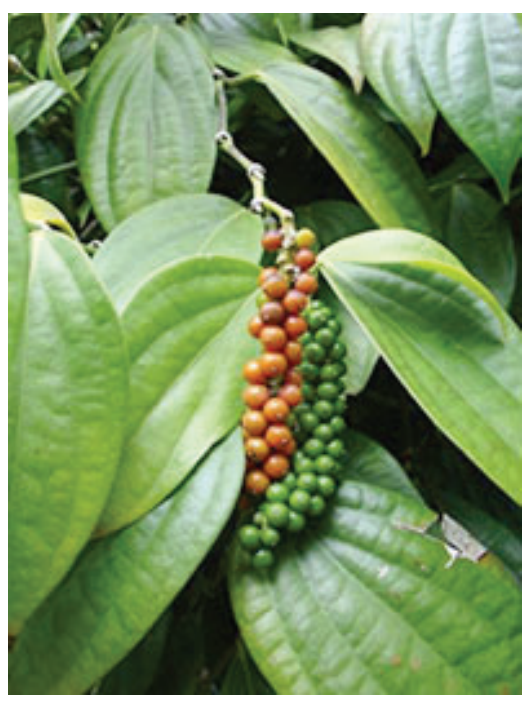

(A)

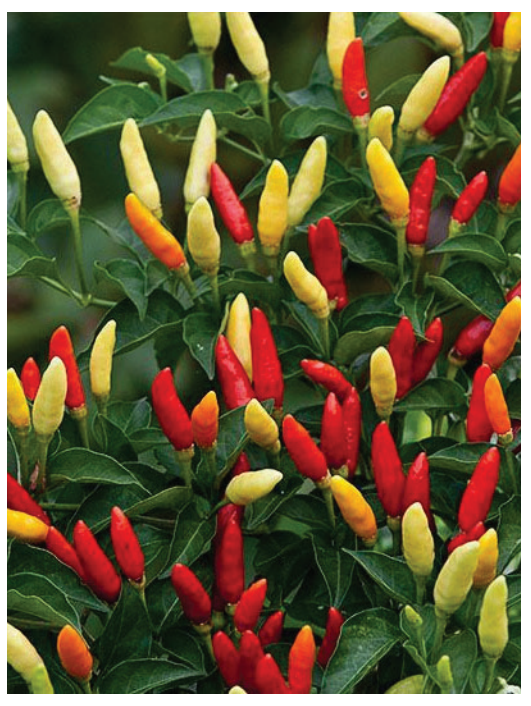

(B)

Figura 2: Pimenta Piper nigrum (A) e Capsicum frutescens (B). Fontes:

A) www.amazon.in/Black-Pepper-Plant-Healthy-Spice/dp/B01N656QXV

B) www.naturalmedicinefacts.info/plant/capsicum-frutescens.html

\section{Principais constituintes}

O fruto da pimenta-vermelha (Capsicum sp. - Solanaceae) é constituído principalmente por: fenilpropanóides: capsaicina, di-idrocapsaicina, norhidrocapsaicina, homocapsaicina; flavonóides: apiosídeo, apigenina, quercetina, luterolina, rutina, campferol; carotenóides: capsantina, capsorru- bina, $\beta$-caroteno, criptoxantina, luteína; lipídeos: ácido linoléico etil éster, ácido linoléico metil éster, ácido palmítico, ácido palmítico metil éster, ácido linolênico metil éster, ácido linolênico etil éster; vitaminas: tiamina, riboflavina, ácido ascórbico, retinóis, folato e sais minerais: manganês, potássio (3,6) (Figura 3). 
<smiles>COc1cc(CNC(=O)CCCC/C=C/C(C)C)ccc1O</smiles>

Capsaicina<smiles>O=c1c(O)c(-c2ccc(O)c(O)c2)oc2cc(O)cc(O)c12</smiles>

Quercetina<smiles>COc1ccc(CNC(=O)CCCCCCC(C)C)cc1O</smiles>

Di-idrocapsaicina<smiles>O=c1cc(-c2ccc(O)c(O)c2)oc2cc(O)cc(O)c12</smiles>

Luteolina<smiles>O=c1cc(-c2ccc(O)cc2)oc2cc(O)cc(O)c12</smiles>

Apigenina

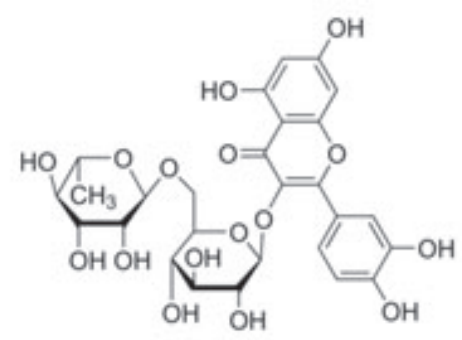

Rutina

Figura 3: Estruturas químicas de alguns componentes do fruto da pimenta-vermelha Fonte: www.sial.com.

Os principais constituintes do óleo-resina do fruto da pimenta-do-reino (Piper nigrum L. - Piperaceae) são: óleo essencial: $\alpha$-pineno, $\beta$-pineno, limoneno, $\beta$-cariofileno, $\Delta^{3}$-careno, sabineno, óxi- do de cariofileno; amidas piperidínicas: piperina, piperoleína B, piperanina, tricholeina; ácidos graxos; ácido palmítico; taninos (traços); fitoesteróides (traços) ${ }^{(1,6)}$ (Figura 4).<smiles>CC1=CCC2CC1C2(C)C</smiles>

a-Pineno<smiles>O=C(/C=C/C=C/c1ccc2c(c1)OCO2)N1CCCCC1</smiles>

Piperina<smiles>C=C(C)[C@H]1CC=C(C)CC1</smiles>

Limoneno<smiles>O=C(/C=C/CCc1ccc2c(c1)OCO2)N1CCCCC1</smiles>

Piperanina<smiles>CC(C)[C@]12CCC(C)(O)[C@H](C1)C2</smiles>

Sabineno

Figura 4: Estruturas químicas de alguns componentes do fruto da pimenta-do-reino Fonte: www.sial.com. 


\section{Alguns usos tradicionais}

A Tabela 1 mostra alguns dos principais usos tradicionais das espécies de pimentas anteriormente relatadas.

Tabela 1: Principais usos tradicionais das espécies de Capsicum sp. - Solanaceae e Piper nigrum L. Piperaceae

\begin{tabular}{ll}
\hline Capsicum sp. - Solanaceae & Piper nigrum L. - Piperaceae ${ }^{\star *}$ \\
\hline Trata: & Trata: \\
- Hidropisia & - Falta de apetite \\
- Cólicas & - Indigestão \\
- Asma & - Tosses \\
- Diarreia & - Gripes e resfriados \\
- Câimbras & - Feridas \\
- Artrite & - Dor de ouvido \\
- Dor de dente & - Dor de dente \\
\hline
\end{tabular}

Fontes: ${ }^{\star}(2)(6) ;{ }^{* \star}(6),(9)$.

\section{Algumas atividades importantes, usos e mecanismos de ação}

A ação antiadipogênica da pimenta-do-reino (Piper nigrum L.) e do seu principal constituinte piperina foi investigada em pré-adipócitos 3T3L1 tão bem quanto os mecanismos moleculares envolvidos. Tanto a pimenta-do-reino quanto a piperina, inibiram acentuadamente a diferenciação das células 3T3-L1. A expressão do mRNA dos principais fatores de transcrição envolvidos na adipogênese (formação de tecido adiposo), tais como PPAR, SREBP-1c e C/EBPB, diminuíram significativamente. Foi comprovado que a pimenta-do-reino e a piperina, atenuam a diferenciação de células adiposas por infrarregulação na atividade de PPARY tão bem quanto a supressão na sua expressão, conduzindo assim a um grande potencial como ferramenta no tratamento de doenças relacionadas à obesidade, tais como diabetes, aterosclerose e muitas outras ${ }^{(4,7)}$.

As espécies vegetais do gênero Capsicum sp. são utilizadas (ex.: Capsicum baccatum Kunth.
- pimenta-dedo-de-moça) como especiaria, tempero, condimento e até alimento principal, sendo fontes de capsaicina, agem inibindo as vias de sinalização de COX-2 e iNOS reduzindo a ação das citocinas pró-inflamatórias e aumentando a atividade de citocinas anti-inflamatórias. Os frutos dessas espécies contribuem para a pretensão anti-inflamatória na nutrição. São ferramentas consagradas pelos benefícios observados em culturas que as adotam em dietas tradicionais ${ }^{(2,3)}$.

O uso tópico do cápsico (Capsicum sp.) é indicado nas dermatites e psoríases. Houve uma considerável redução no espessamento, eritema e prurido das áreas lesadas em ensaios em humanos com quadros de moderado a severo. O principal efeito adverso relatado foi breve ardência no local da aplicação. A capsaicina (fenilpropanóide - principal constituinte) é contraindicada em feridas abertas, proximidades dos olhos, na gravidez e lactância ${ }^{(2,5,11)}$ (Tabelas 2 e 3). 
Tabela 2: Algumas preparações e os usos potenciais de espécies de Capsicum sp. - Solanaceae.

\begin{tabular}{|c|c|}
\hline Fruto inteiro & Capsaicina \\
\hline Anti-inflamatório, analgésico & Anti-inflamatória, analgésica \\
\hline ^Inibidor da peroxidação lipídica & Inibidora da peroxidação lipídica \\
\hline $\begin{array}{l}\text { Estimulante digestivo, carminativo, anties- } \\
\text { pasmódico }\end{array}$ & $\begin{array}{c}\text { Estimulante digestivo, carminativa, antiespas- } \\
\text { módica }\end{array}$ \\
\hline Indutor de glicoproteína $\mathrm{P}$ & ^Indutor de glicoproteína $\mathrm{P}$ \\
\hline Antitumoral, antimutagênica & Antitumoral, antimutagênica \\
\hline $\begin{array}{c}\downarrow \text { Inibidor de alfa-amilase e } \uparrow \text { alfa-glicosidase } \\
\text { intestinal }\end{array}$ & $\begin{array}{c}\downarrow \text { Inibidora de alfa-amilase e } \uparrow \text { alfa-glicosidase } \\
\text { intestinal }\end{array}$ \\
\hline Termogênico e inibidor de adipogênese & Termogênica e inibidora de adipogênese \\
\hline Antidislipidemias & Antidislipidemias \\
\hline
\end{tabular}

Fontes: (2), (3), (5), (8), (11).

Tabela 3: Algumas preparações e os usos potenciais de espécies de Piper nigrum L. - Piperaceae

\begin{tabular}{|c|c|}
\hline Pó do fruto & $\begin{array}{c}\text { Fração de Amidas Piperidínicas e Piperina } \\
\text { isolada }\end{array}$ \\
\hline Anti-inflamatório & Anti-inflamatórias \\
\hline Inibidor da peroxidação lípídica & Inibidoras da peroxidação lipídica \\
\hline Estimulante digestivo & Estimulantes digestivas \\
\hline $\begin{array}{c}\text { Inibidor de enzimas metabolizadoras UDP- } \\
\text { glucoronil-transferase, UDP-glicose desidroge- } \\
\text { nase, glicoproteína P, citocromo p450 }\end{array}$ & $\begin{array}{c}\text { Inibidoras de enzimas metabolizadoras UDP- } \\
\text { gluconil-transferase, UDP-glicose desidroge- } \\
\text { nase, glicoproteína P, citocromo p450 }\end{array}$ \\
\hline Antitumoral, antimutagênica & Antitumorais, antimutagênicas \\
\hline Inibidor de aflatoxinas & Inibidoras de aflatoxinas \\
\hline Termogênico e inibidor de adipogênese & Termogênicas e inibidoras de adipogênese \\
\hline
\end{tabular}

Fontes: (4), (7), (8), (9), (10).

\section{Toxicidade e interações}

\section{Capsicum sp. - Solanaceae}

O uso excessivo dos frutos das espécies vegetais do gênero Capsicum sp. deve ser evitado em portadores de gastrite, úlceras pépticas e duode- nais, síndrome do colón irritável, durante a gravidez e lactação. As espécies desse gênero botânico podem provocar dermatite de contato. É prudente ter cautela ao associar com agentes adrenégicos de ação central (clonidina, metildopa), inibidores da MAO (hipertensão), anticoagulantes, corticóides e anti-inflamatórios ${ }^{(2,6)}$. 


\section{Piper nigrum L. - Piperaceae}

A piperina utilizada excessivamente e isolada, causa diminuição no tamanho dos testículos, diminuição na quantidade de esperma e diminuição na quantidade de testosterona. $\mathrm{O}$ uso excessivo e persistente de pimenta-do-reino pode ocasionar problemas no parênquima renal, o que pode ser prevenido e revertido com alto consumo de fontes seguras de taninos (ex.: frutos de Psidium guajava L., Malus domestica Borkh, Vitis vinífera L, Anacardium occidentale L., Eugenia uniflora L., Punica granatum L.) ${ }^{(9,10)}$.

As quantidades adotadas em temperos simples e associados raramente apresentam alguma contra -indicação, com exceção nos casos de hipersensibilidades.

\section{Conclusão}

Através do levantamento publicado nesse artigo pode-se concluir que o fruto das espécies vegetais do gênero Capsicum sp - Solanaceae e da Piper nigrum L. - Piperaceae apresentam um grande potencial como ferramentas terapêuticas podendo ser aplicadas desde em tratamento de doenças relacionadas a processos inflamatórios crônicos e à síndrome metabólica tais como obesidade e dislipidemias até em problemas relacionados ao envelhecimento ao câncer, com relação direta à presença do derivado fenilpropanóide capsaicina nas espécies do gênero Capsicum sp, assim como à piperina isolada a partir da fração de amidas piperidícas na espécie Piper nigrum L. - .

No entanto, deve-se haver cautela ao utilizar preparações constituídas por essas espécies vegetais assim como desses fitofármacos na gravidez, lactância e em portadores de problemas gastrintestinais, embora sejam indicados como estimulantes digestivos, carminativos e antiespasmódicos. $\mathrm{Na}$ associação com medicamentos é prudente que se administre durante ou logo após dietas balanceadas e diversificadas ao ponto de minimizar a inibição e a indução de processos protéicos e enzimáticos metabolizadores, no entanto, as quantidades adotadas em temperos simples e associados rara- mente apresentam alguma contra-indicação, com exceção nos casos de hipersensibilidades.

\section{Referências bibliográficas}

1. Kapoor, I.P.S.; Singh, B.; Singh, G., De Heluani, C.S.; De Lampasona, M.P.; Catalan, C.A.N., J. Sci. Food Agric. 2009; 57: 5358-5364.

2. Khotari, S.L.; Joshi, A.; Kachhwaha, S.; Ochoa-Alejo, N., Biotechnol. Adv. 2010; 28: 35-48.

3. Loizzo, M.R.; Pugliese, A.; Bonesi, M.; De Luca, D.; O'Brien, N.; Menichini, F.; Tundis, R., Food Chem.Toxicol. 2013; 53:392-401.

4. Mueller, M.; Beck, V.; Jungbauer, A., Planta Med. 2011; 77: 497-504.

5. Nakamura, A.; Shiomi, H., Jpn. J. Pharmacol.1999; 79: 427-431.

6. Panizza, S.T.; Veiga, R.S.; De Almeida, M.C., Uso Tradicional de Plantas Medicinais e Fitoterápicos, Conbrafito, Metha Ed., 2012, 267 pg.

7. Park, U.H.; Jeong, H.S., Jo, E.Y.; Park, T.; Yoon, S.K.; Kim, E.J.; Jeong, J.C.; Um, S.J., Agric. Food Chem. 2012; 60:3853-3860.

8. Rao, R.R.; Platel, K.; Srinivasan, K., Nahrung/ Food 2003; 47(06): 408-412.

9. Singletary, K., Nutrition Today 2010; 45(01): 43-47.

10. Srinivasan, K., Critical Review in Food Sci. Nutr.v. 47, p.735-748, 2007.

11. Wood, J.N.; Docherty, R., Annu, Rev. Physiol., v. 59, p. 457-482, 1997. 